\title{
Common swelling of the dorsal thoracic wall brings an unexpected finding: elastofibroma dorsi
}

\author{
Sotirios Kotoulas $^{1}$, Konstantinos Grapatsas ${ }^{2}$, Charalampos Georgiou ${ }^{3}$, Zoi Tsilogianni ${ }^{4}$, \\ Vasileios Leivaditis ${ }^{2}$, Mariana Braga Lopes Rufino ${ }^{1}$, Christophoros Kotoulas ${ }^{3}$ \\ ${ }^{1}$ Faculty of Medicine, Charles University in Prague, Pilsen, Czech Republic; ${ }^{2}$ Department of Thoracic Surgery, \\ Medical Center-University of Freiburg, Faculty of Medicine, Germany; ${ }^{3}$ Department of Thoracic Surgery Bioclinic, \\ Athens, Greece; ${ }^{4}$ Department of Pneumonology, Attikon University Hospital of Athens, Greece
}

\begin{abstract}
Elastofibroma is a rare benign, soft-tissue slow-growing tumor seen predominantly in elderly females. We present such a case in a 46-year-old female. She presented with gradually increasing soft tissue swelling of $8 \times 6 \mathrm{~cm}$ in the right inferior subscapular region. MRI showed a large intramuscular lesion with atypia. She underwent excisional biopsy and the histopathology and immunochemistry showed elastofibroma. We present this rare case to emphasize the important role of the diagnostic tools. A definitive diagnosis helps to avoid unnecessary wide and radical resection.
\end{abstract}

\section{Introduction}

A swelling at the patient's dorsal thoracic wall can be attributed to many causes. Elastofibroma is one of the rare causes, with limited reported cases, that could be easily missed from the differential diagnosis of the general practitioner as well as the thoracic

Correspondence: Dr. Christophoros Kotoulas, Department of Thoracic Surgery Bioclinic of Athens, Kifissias Ave 38, Athens 11526, Greece. Tel. +30.2107782220

E-mail: info@kotoulas.com

Key words: Benign; tumor; thoracic wall; surgery; MRI.

Contributions: All the Authors contributed equally. All the authors have read and approved the final version of the manuscript and agreed to be accountable for all aspects of the work.

Conflict of interest: The Authors declared.

Received for publication: 26 August 2019.

Accepted for publication: 3 December 2019.

${ }^{\circ}$ Copyright: the Author(s), 2020

Licensee PAGEPress, Italy

Monaldi Archives for Chest Disease 2020; 90:1159

doi: 10.4081/monaldi.2020.1159

This article is distributed under the terms of the Creative Commons Attribution Noncommercial License (by-nc 4.0) which permits any noncommercial use, distribution, and reproduction in any medium, provided the original author(s) and source are credited. surgeon [1]. Herein, we report such a rare tumor, discussing the international literature.

\section{Case Report}

A 58-year-old Caucasian female complained for diffuse soft-tissue swelling in the back, which had been present and gradually growing for the last year, with pain in her right shoulder while elevating her arm or when sitting. Chest $\mathrm{x}$-ray and blood tests were normal. Chest CT Scan showed a probable second to third degree strain of the right serratus anterior muscle. MRI revealed a $9 \times 9 \times 3 \mathrm{~cm}$ lesion in the posterior lateral border of the serratus anterior including a focal ill-defined altered signal intensity lesion (Figure 1).

Surgical resection was recommended due to the MRI untypical findings. Skin incision was performed above the mass. The Latissimus Dorsi muscle was divided and the tumor along with some surrounding fat tissue was resected (Figure 2). Negative pressure was applied to facilitate wound healing.

Histopathology showed a mesenchymal tumor $11 \times 8,5 \times 3,5 \mathrm{~cm}$, composed of collagenous areas surrounding mature fat tissue. The tumor had fatty and fibrous consistency. Verhöff-Van Gieson stain revealed the presence of fibrous and elastic cells. Immunochemistry stains were positive for Vimentin and negative for SMA, S100, desmin and B-catenin. The diagnosis of elastofibroma was confirmed. Her recovery was uneventful. She is symptom-free and disease-free, three years later.

\section{Discussion}

Järvi and Saxén were the first to describe the term elastofibroma in 1961 [2]. Although WHO defined elastofibroma dorsi as a real tumor, most authors do consider as a hyperplasia of elastic tissue derived from fibroblasts due to chronic friction. There have been described three theories. First, that is the chronic and repetitive mechanical stress leads to microtrauma, then to overproduction of elastic tissue from the stimulated fibroblasts. Second, the reactive fibromatosis and secondary degeneration of elastic fibers due to vascular insufficiency. Third, a familial predisposition with an underlying enzymatic disorder or defect, reported by Fukuda et al. [3].

It is a palpable, moveable mass without distinct borders. The vast majority of the tumors ( $>90 \%$ ) appears between the inferior angulus and medial margo of scapula, ventral to the serratus anterior between the $6^{\text {th }}$ and $8^{\text {th }}$ rib [4]. Studies reported a prevalence of $2 \%$ 
in asymptomatic patients, and a prevalence of $24 \%$ in women and $11 \%$ in men in autopsy series [5]. There is no specific symptomatology. Symptoms have been reported such as discomfort during movement, swelling on the thoracic wall, periscapular pain, scapular snapping, limitation of movement, clunking sensation in adduction and abduction of the shoulder. As a result of the discomfort, sleep disorders might also occur. Because of the rarity of the disease as well as the low severity of the symptomatology, the diagnosis of the tumor could be delayed [6,7]. As in our case, when the elastofibroma is found in the periscapular region it is characterized as elastofibroma dorsi. Its occurrence is $47.9 \%$ unilaterally on the right side, $35.2 \%$ unilaterally on the left and $16.9 \%$ bilaterally. However, the range for bilateral occurrence varies between $10-30 \%$ [6].

The diagnosis of elastofibroma is challenging due to its muscle like appearance. A careful physical examination and imaging is nec-

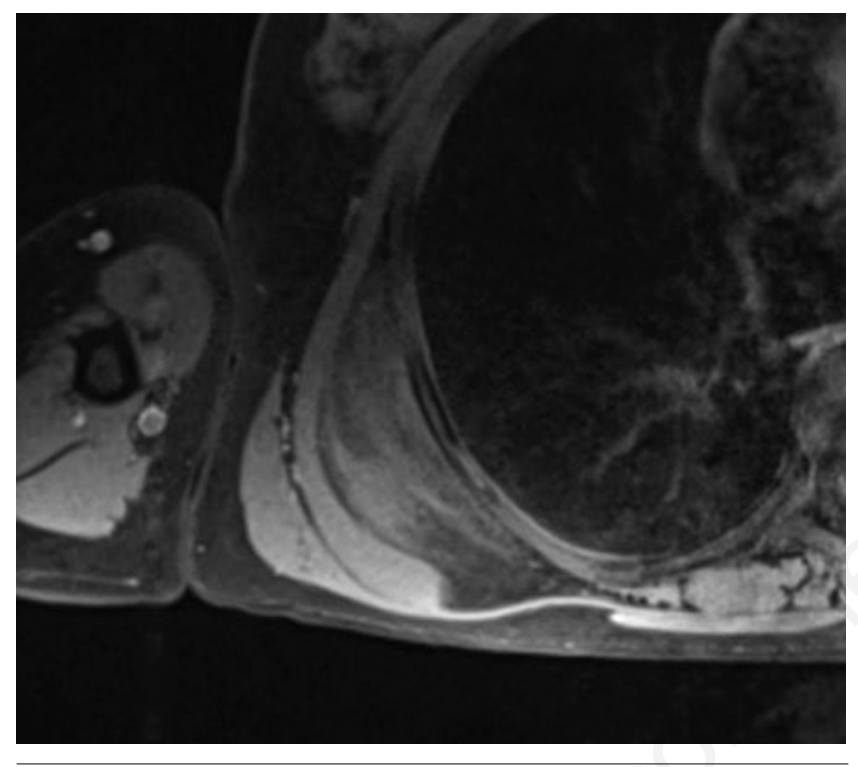

Figure 1. MRI revealed a 9x9x3 cm lesion in the posterior lateral border of the serratus anterior including a focal ill-defined altered signal intensity lesion.

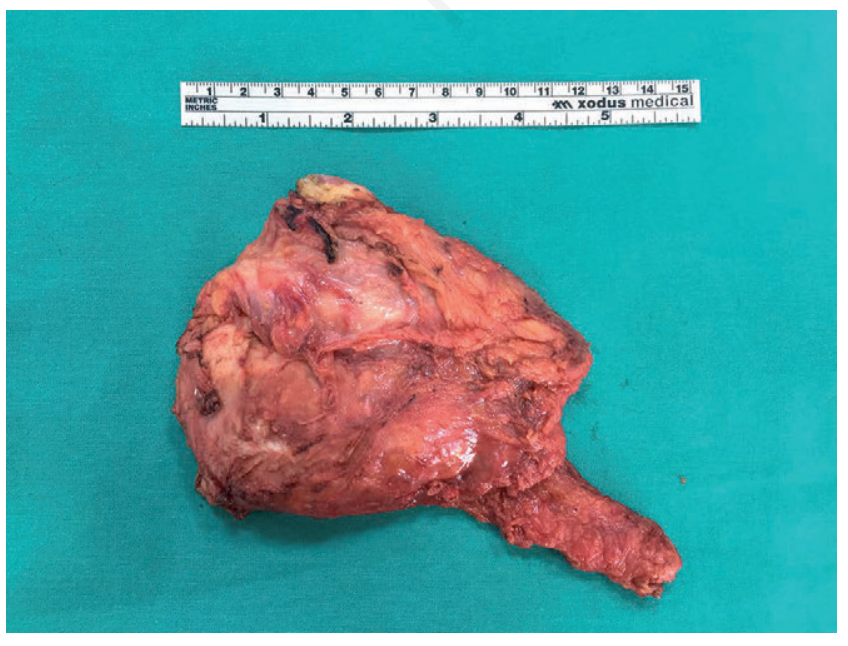

Figure 2. The excised lesion. essary. Chest X-ray shows unspecific images of elevation of the scapula and an enlargement of the scapulothoracic space. Ultrasound examination shows an alternating of hypoechogenic and hyperechogenic striations similar to muscle and parallel to its major axis [3]. Battaglia et al. suggested 4 patterns of sonographic types [4]. CT scan shows a non-homogeneous mal limited mass with density similar to muscles, including areas of lower density secondary to fat [1]. In only $2 \%$ of the cases the tumor was revealed by CT [8]. MRI remains the gold standard examination for diagnosis [1]. MRI reflects the histological composition of entrapped fat within a predominantly fibrous mass. MRI imaging provides also specific features to establish differential diagnosis between sarcoma, liposarcoma, hemangioma, hematoma, lipoma and several other lesions [3]. On 18-FluoroDeoxyGlucose (18-FDG) PET-CT, accumulation of the hypermetabolic tumor can be seen [5].

There is a debate concerning the necessity of a biopsy. Draigeler et al. recommend a preoperative open biopsy or a core biopsy in order to collect a broader sample leading to a more accurate diagnosis [9]. However, if biopsy cannot exclude a malignancy, then the surgical resection even in asymptomatic patients is the treatment of choice. The definitive diagnosis of the tumor can only be made through histopathological examination of the mass.

Treatment is provided in symptomatic painful forms, or when the diagnosis is doubtful. It consists in complete surgical excision of the mass with curative marginal resection. Lesions bigger than $5 \mathrm{~cm}$ must undergo excisional surgery [6]. Careful preoperative planning of the operation and application of negative pressure drainage must be applied to facilitate wound healing and reduce the remaining anatomical dead space and the postoperative seroma [6].

As a conclusion, lesions located deep beneath the inferior tip of the scapula in the chest wall should arouse suspicion of an elastofibroma. MRI is the gold standard examination for diagnosis. Excisional biopsy-resection is the therapeutic option for symptomatic patients and untypical lesions to rule out a malignant tumor diagnosis.

\section{References}

1. Patnayak R, Jena A, Settipalli S, Nagesh N. Elastofibroma. An uncommon tumor revisited. J Cutan Aesthet Surg 2016;9:34-37.

2. Jarvi O, Saxen E. Elastofibroma dorsi. Acta Pathol Microbiol Scand (Suppl) 1961;51:83-4.

3. Karrakchou B, Yaikoubi Y, Said Chairi M, Jalil A. Elastofibroma dorsi: case report and review of the literature. Pan Afr Med J 2017;28:34.

4. Battaglia M, Vanel D, Pollastri $P$, et al. Imaging patterns in elastofibroma dorsi. Eur J Radiol 2009;72:16-21.

5. Goyal P, Gandhi D, Gupta S, et al. Elastofibroma dorsi. Proc (Bayl Univ Med Cent) 2017;30:340-342.

6. Lococo F, Cesario A, Mattei F, et al. Elastofibroma dorsi: clinicopathological analysis of 71 cases. Thorac Cardiovasc Surg 2013;61:215-22.

7. Pilge H, Hesper T, Holzapfel BM, et al. Elastofibroma: clinical results after resection of a rare tumor entity. Orthop Rev (Pavia) 2014; 16;6:5329.

8. Brandser EA, Goree JC, El-Khoury GY. Elastofibroma dorsi: prevalence in an elderly patient population as revealed by CT. AJR Am J Roentgenol 1998;171:977-80.

9. Daigeler A, Vogt PM, Busch K, et al. Elastofibroma dorsi - differential diagnosis in chest wall tumours. World J Surg Oncol 2007;5:15. 